\title{
Kendi Enerjisini Üretebilen Klavye Tasarımı
}

\author{
Alper ŞENYÜREK ${ }^{1}$, Mustafa DEMETGÜL ${ }^{2}$ \\ ${ }^{1}$ İnönü Mesleki ve Teknik Anadolu Lisesi, Bayrampaşa, İstanbul, \\ ${ }^{2}$ Marmara Üniversitesi, Teknoloji Fakültesi, Mekatronik Mühendisliği, Kadıköy, İstanbul
}

\section{Özet}

Üretimdeki gelişmeler, düşük güçlerde çalışan devre tasarımları ve ağ tekniklerini ortaya çıkarmıştır. Bu nedenle elektronik cihazların güç gereksinimleri azalmıştır. Enerji sistemlerindeki azalan güç ihtiyacı, pillere alternatif sistemlerin kullanılma olasılı̆̆ ile birlikte farklı aygıtların ortaya çıkmasına sebep olmuştur. Enerji ile çalışan aygıtlarda ortamdaki hareket enerjisinin yakalanması ve bu enerjinin kullanılabilir elektrik enerjisine dönüştürülmesi için piezo elektrik malzemeler kullanılması mümkündür. Bu çalışmada farklı klavyelere uygulanabilecek çeşitli genişlik ve uzunluklarda piezo elektrik malzemeler ve yaylar kullanılmıştır. Uygulanan kuvvete bağlı olarak piezo elektrik üzerinde oluşan gerilmelerle elektrik enerjisi üretilmiştir.

Anahtar Kelimeler: Piezo elektrik, enerji depolama, mikro enerji, klavye, basma kuvveti.

\section{Keyboard Design Producing its Own Energy}

\begin{abstract}
The development in production has posed circuit patterns operating in low energy and network techniques. Therefore the energy requirements for electronic devices have decreased. With decreased demand in energy systems, besides the probable use of devices alternative to batteries, new devices have been emerged. Piezoelectric materials have been used in power operated devices in order to capture the kinetic energy in the media and to convert it into usable electrical energy. In this work piezo electric material applicable to various keyboards with various with and length dimensions and spring configurations were used. Depending on the applied force, electrical energy was generated by the stress induced on the piezo electric device.
\end{abstract}

Keywords: Piezo-electric, energy storage, micro power, keyboard, pressing force

\section{GIRISŞ}

Enerji günümüzde bütün dünyanın en önemli sorunlarından birisidir. Enerji ihtiyacı gün geçtikçe birçok nedenden dolayı artmakta ve üretim-tüketim arasındaki fark da gün geçtikçe açılmaktadır. Bunun başlıca nedenleri; nüfus artışı, teknolojik gelişmeler, sanayileşme ve insanların yaşam konforudur. Fosil kaynaklı enerjiler sonsuz değildir ve bir gün tükenecekleri 
sabit bir gerçektir. Bunun sonuçları da bütün dünya ekonomisini etkileyecek kadar büyük olabilecektir. Bu durum alternatif enerji kaynaklarının önemini ortaya çıkarmaktadır.

Alternatif enerji kaynakları ise, doğada var olan temiz ve yenilenebilir enerji kaynaklarıdır. $\mathrm{Bu}$ enerji kaynaklarının kendini yenileyebilir özellikte olmaları, ekonomik olmaları ve çevreye çok az zarar vermeleri, gelişmiş ülkelerin bu tür kaynaklara yatırım yapmalarını sağlamış ve teknolojilerinin hızla gelişmesine neden olmuştur[1].

Farklı sensör teknolojileri hem piezo elektrik hem de geleneksel olmayan dönüştürücü teknolojilerini içermektedir [2-4]. Son yıllarda bu teknolojiler en popüler araştırma konularından biri olmuştur [5]. Üretimdeki gelişmeler düşük güçlerde çalışan devre tasarımları ve ağ tekniklerini ortaya çıkarmıştır [6]. Küçülen katı hal elektronik cihaz denetimleri insanları daha savunmasız yapmıştır [7]. Bu nedenle elektronik cihazların güç gereksinimleri azalmıştır. Azalan güç talebiyle enerji sistemleri pillere alternatif sistemlerin kullanılma olasılığı ile birlikte alternatif aygıtları ortaya çıkarmıştır [8-11]. Bu aygıtlar tıbbi endüstriyel ve askeri uygulamalarda ve bu sistemlerin güç harcamalarında kullanılmak üzere kendi enerjisini üreten küçük ve verimli cihazlara ihtiyaç uyandırmıştır [12-13]. Enerji ile çalışan aygıtlarda ortamdaki hareket enerjisinin yakalanması ve kullanılabilir elektrik enerjisine dönüştürülmesi için piezo elektrik malzemeler kullanılmıştır [14-16]. Piezo elektrik, Yunanca piezo kelimesinden türetilmiş olup, basınç uygulamak, sıkıştırmak anlamlarına gelmektedir[17-19]. Bu malzemeler bir elektrik potansiyeli uygulamadan piezoelektrik malzemeden mekanik deformasyon ile gerilim üretme anlamını taşımaktadır[20]. Harcanan ya da kullanılmayan bu mekanik hareketten elektrik enerjisi elde edilmesi tartışma konusu olmuştur [21]. Normalde kaybolan ortam titreşiminden yararlanarak tamamen kendi gücünü üreten elektronik cihazlar geliştirilmektedir.

$\mathrm{Bu}$ titreşimden enerji elde etmek için bir çok yöntem var iken piezo elektrik malzemeler ön plana çıkmaktadır. $\mathrm{Bu}$ yaklaşımın uygulaması, klasik yöntemlerden daha pratiktir[22]. Bükme, esneme ve basınç algılama için piezo elektrik malzeme kullanılabilir[23].

Piezo elektrik malzemeler; akıllı ayakkab1, akıllı elbise, akıllı araba ve buna benzer örneklerde dahil olmak üzere geniş bir yelpazede kullanılmaktadır [24-25].

Literatürdeki araştırmalarda çeşitli tasarımlar mevcuttur. Bunlardan Bai ve Yang yaptıkları çalışmada kablosuz klavyenin ihtiyacı olan enerjiyi üretmek için güneş enerjisinden yararlanmışlardır. Bai ve Yang klavye üzerine güneş hücreleri yerleştirmiş bu sayede güneşten aldıkları 1sı enerjisini büyük kapasitörler vasıtasıyla depolamışlardır[19]. Külah ve arkadaşları ise elektromanyetik ve piezo elektrik bir yapı tasarlamışlardır. Bu sayede hibrid bir teknoloji elde etmişlerdir. Klavye tuşları üzerine uygulanan kuvvet vasıtasıyla piezo 
elektrik malzemeden elektrik enerjisi üretirken aynı zamanda oluşturduğu manyetik alandan yine elektrik enerjisi sağlamıştır [9]. Rofouei ve arkadaşları klavye tuşları altına yerleştirdikleri sensörler vasıtasıyla elektrik enerjisi üretmişlerdir[5]. Wang ve Liu ise farklı olarak özel olarak yerleştirdikleri boru sisteminden akış sağlayarak piezo elektrik malzemenin genleşmesini sağlayarak enerji elde etmiştirler[25].Uşaklı ve Gürkan ise yine farklı olarak kafa üzerine yapıştırdıkları algılayıcılardan felçli hastaların bilgisayar yardımıyla isteklerini anlatabilmelerini sağlamışlardır [17].

$\mathrm{Bu}$ bağlamda literatürdeki diğer çalışmalardan farklı olarak klavye tuşları altına yerleştireceğimiz farklı boyutlardaki piezo elektrik malzemeler sayesinde hem piezo elektrik malzemenin üzerine uygulanan kuvvetten yararlanılacak hem de bu malzemenin esneme özelliğinden yararlanılacaktır. Bu sayede hibrid bir sistem sağlanacaktır.

\section{Akıllı Malzeme}

Çevrelerindeki değişimlere duyarlı olabilen ve önceden belirlenen, usullerde bu değişimlere cevap veren yaşayan organizmalarda bulunan özelliklere sahip malzemelerdir. Günümüzde mekanik ve malzeme bilimindeki gelişmeler ve eş zamanlı olarak ortaya çıkan dizayn ve imalat teknolojilerindeki ilerlemeler çok sayıda yeni ve ileri derecede mühendislik malzemesi üretti. Bu fonksiyonel malzemeler, mekanik, elektrik, manyetik alan veya 1sınma gibi bir diş fiziksel olayın etkisinde kaldığı zaman şeklini ve maddesel özelliklerini değiştirme konusunda farklı davranışlar sergilerler[26].

\subsection{Piezo elektriksel Davranış}

Mekanik bir kuvvete maruz kalındığında kristaller elektrikle yüklenir.Bu kristallerin yapmış olduğu hareketleri inceleyen Curie kardeşler piezo elektriksel davranışı keşfettiler. Piezo elektriksel davranış; iletken olmayan billurdan, yontulmuş bir levhadan belli bir doğrultuda uygulanan kuvvet ve sıkıştırma sonunda, billur levhanın iki yüzünde zit polariteli yüklerin (+ ve -) çıkmasıyla tanımlanan bir olaydır[27] .Şekil 1 de bu zit polaritelerin yer değişimi gösterilmiştir.

Bilindiği gibi katı maddeler, yüklü parçacıklardan oluşur ve bir katı madde içindeki negatif ve pozitif yüklü parçacıklar dengededir (yani katı madde elektriksel olarak yüksüzdür). Ancak mekanik bir yolla malzeme üzerine mekanik bir kuvvet uygulanarak, yüzey yüklerinin oluşması sağlanabilir. Bir kristalde piezoelektrik özelliğin gözlenmesi bu yüzey yüklerinin oluşmasına bağlıdır[28]. Fakat simetri özellikleri bu yüklerin oluşması için gerekli koşulları kısıtlamaktadır. Bu nedenle simetri merkezi olmayan kristaller bu iş için en uygun malzeme 
grubunu oluşturmaktadır [27]. Elektriksel olarak yüksüz ve yapısal simetri merkezi bulunmayan bir kristalde uygulanan basınç artı yüklerin merkezi ile eksi yüklerin merkezinin birbirinden hafifçe ayrılmasına ve kristalin karşılıklı yüzeylerinde zıt yüklerin ortaya çıkmasına neden olur. Yüklerin bu şekilde ayrılması bir elektrik alanı yaratır ve kristalin karşılıklı yüzeyleri arasında ölçülebilir bir potansiyel fark oluşur[28].

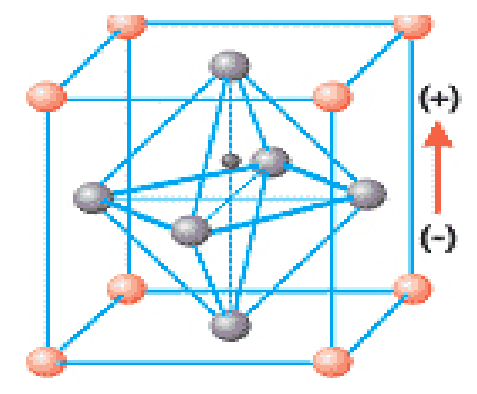

Şekil1. Piezo'nun kristal yapısı [27]

\section{Tasarım}

Piezo elektrik malzemeler elektrik enerjisini mekanik enerjiye, mekanik enerjiyi elektrik enerjisine çevirme yeteneğine sahip malzemeler oldukları için bu özelliklerden yararlanılarak algılayıcı (sensör) ve tetikleyici (actuator) olarak sıkça kullanılmaktadırlar. Elektrotlar yardımı ile bir gerilim uygulandığında mekanik bir hareketle cevap vermesi veya mekanik bir baskı sonucunda bünyesine bağlanan elektrotlardan gerilim elde edilmesi bu sert malzemelerin öncelikli olarak yapısal sistemlerinin üzerine araştırma yapılmasını ortaya çıkarmıştır. $\mathrm{Bu}$ araştırmada şekil 2 ve şekil 3 de görüldüğü üzere klavye içerisine yerleştirilmek üzere iki çeşit piezo elektriksel malzeme kullanılmıştır. Bu malzemelerden levha şeklindeki piezo Cat.\#40-2010 American piezoda üretilmiş olup özellikleri uzunluk (L) 60 mm Genişlik (W) 20 mm Kalınlık (T) 0.69 mm üretebildiği gerilim aralığı DC $150 \mathrm{~V}$ ve en az üzerine uygulanabilecek minimum kuvvet $500 \mathrm{mN}$ büyük uygulaması olan bir piezo malzemedir. Diğer kullandığımız piezo elektriksel malzeme ise disk şeklinde olup D-.500".200"-850WFB koduyla American piezo tarafından üretilmiş ve özellikleri Çapı (D) 0.500 inch, Kalınlığı (t) 0.20 inch' dir.

Bir nolu tasarımda levha piezo elektrik malzeme üzerine uygulanan kuvvet, yayın oturmuş olduğu piezo elektrik malzeme üzerinde yayılı bir yük oluşmasına neden olur. Yayılı yük piezonun eğilme gerilmesi tesiri altında kalmasına, piezo elektriksel davranış göstermesine neden olur ve elektrik enerjisi üretilmiş olur. Klavye tuşunu altına yerleştirmiş olduğumuz 
disk şeklindeki piezo ile hem yayın basma kuvveti hem de üzerine uygulanan kuvvet ile piezonun elektrik enerjisi üretmesi sağlanmıştır.

Tasarımda yaylar kullanılmış ve bu yaylar vasıtasıyla piezo malzemelerin eğilme, basma kuvvetlerine vermiş oldukları tepki-kuvvet gerilim dönüşümleri incelenmiştir.

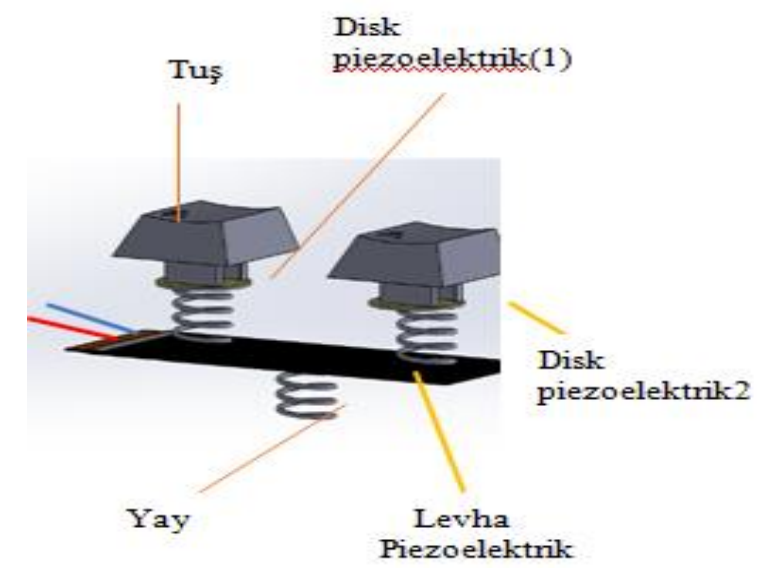

Şekil 2. Klavye içerisinde bir nolu sistem tasarım

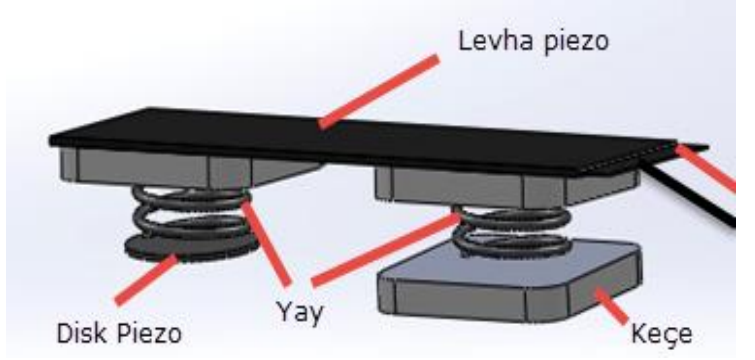

Şekil 3. Klavye içerisinne iki nolu sistem tasarımı

İki nolu tasarım ise Şekil 3 de gösterilmiştir. Tasarımda bir adet levha piezo ve bir adet disk piezo kullanılmıştır. Bu çalışmada levha piezonun alt tarafına iki adet keçe yapıştırılmıştır. Keçelerin üstüne yaylar silikonlanmıştır. Bir yayın altına disk şeklindeki piezo, diğer taraf da ise keçe sabitlenmiştir. Tasarım klavyenin içine yerleştirilmek için hazırlanmış olup klavyeye Şekil 4 de gösterildiği şekilde yerleştirilmiştir.

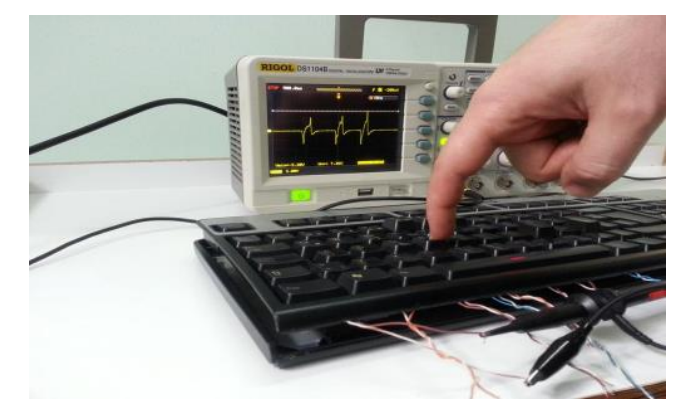

Şekil 4. Tasarımların yerleştirildiği klavye düzeneği 


\section{Deney}

$\mathrm{Bu}$ deneyde şekil 5 de gösterildiği gibi piezo elektrik sistemimiz üzerine uygulamış olduğumuz mekanik hareketten elektrik enerji dönüşümleri incelenmiş olup üzerine uygulanan kuvvet ile piezo elektriksel malzeme içerisindeki atomların yer değiştirmesi doğrultusunda elektrik enerjisi anlık bir şekilde üretilmiş ve bu elektrik enerjisinin diğer sistemlerde nasıl kullanacağ

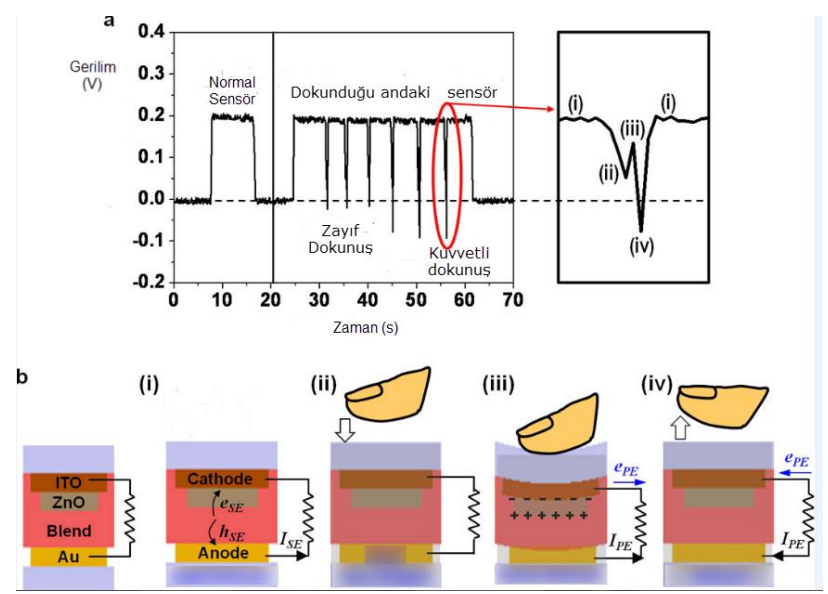

Şekil 5. El kuvvetinin piezo-sensör üzerindeki değişimi

Yaptığımız çalışmalarda insan elinin bir klavye tuşuna normal basma kuvveti yaklaşık 3N luk bir kuvvet olarak saptanmıştır. $\mathrm{Bu}$ sistemlerde yaylarımız olduğu için, tasarımlarımıza yaklaşık $5 \mathrm{~N}$ luk bir kuvvet uygulamak daha doğru olacaktır.

Birinci tasarımda klavye üzerine bir kuvvet uygulandığı zaman oluşan gerilmeler Şekil 6 da gösterilmiştir. Şekil 6 daki grafik incelendiğinde yaklaşık $14 \mathrm{~V}$ luk bir gerilim ürettiği gözlenmiştir. Akım $(0,060 \mathrm{~mA})$ düşük olmasına rağmen oluşan güç $840 \mu \mathrm{W}$ olarak ortaya çıkmıştır.

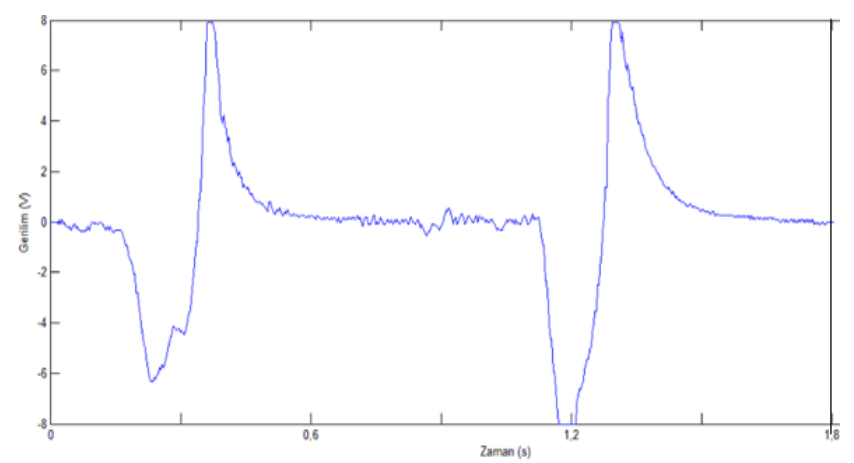

Şekil 6. Levha piezo elektriğin zamana bağlı değişimi 
Birinci, tasarımda yer alan diğer iki adet disk piezo ise, şekil 7 de gösterilen gerilim- zaman dönüşümüne göre yaklaşık 2,7 volt üretmiştir. Ölçülen akım değeri 0,038 mA disk piezonun gücü 102,6 $\mu \mathrm{W}$ cinsinden bir güç elde etmemizi sağlamıştır.

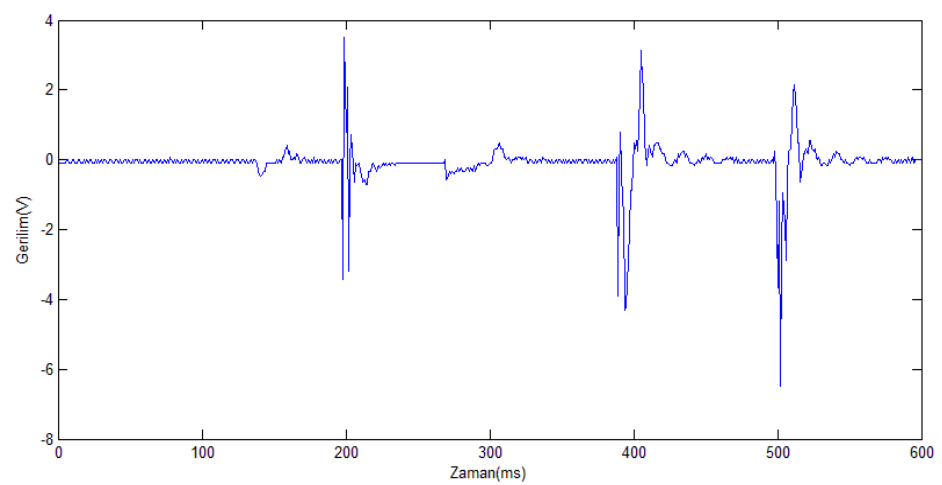

Şekil 7. Disk piezo elektriğin zamana bağlı değişimi

İkinci tasarım da yaptığımız deneyde gerilim-zaman dönüşümü şekil 8 deki grafikte gösterilmektedir. Grafiğe göre; levha piezo yaklaşık olarak $10 \mathrm{~V}$ luk bir gerilim üretimi sağlamıştır. Akım olarak; 0,041 mA lik bir akım geçmektedir ve üretilen güç yaklaşık 410 $\mu \mathrm{W}$ olarak hesaplanmıştır.

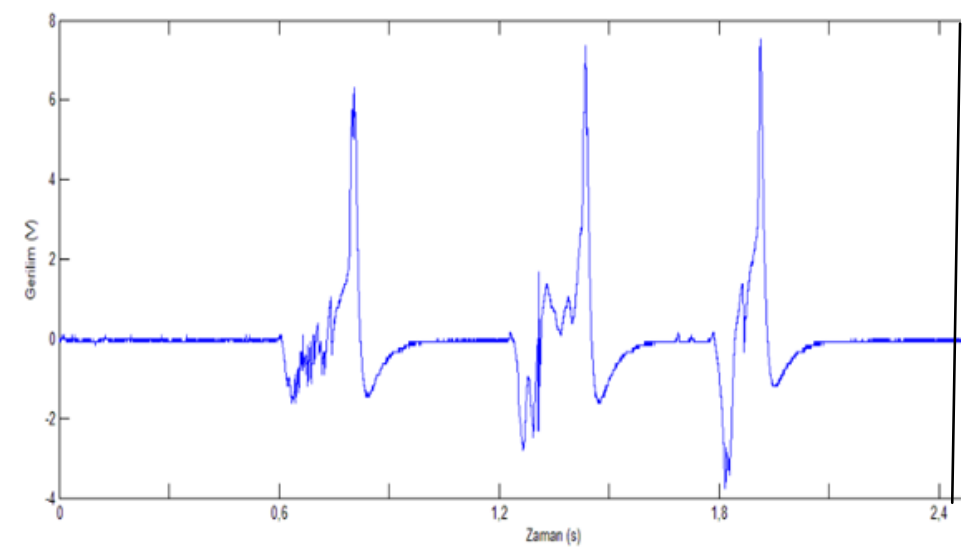

Şekil 8. Disk şeklindeki piezo elektriğin zamana bağlı değişimi

Şekil 9 da ki grafikte disk piezoların gerilim-zaman dönüşümü incelenmiş olup ortaya çıkan 3,5 V' luk gerilimle elektrik enerjisi üretilmiştir. Akım değeri 0,035 mA dır. Üretilen güç yaklaşık olarak $122,5 \mu \mathrm{W}$ tır 


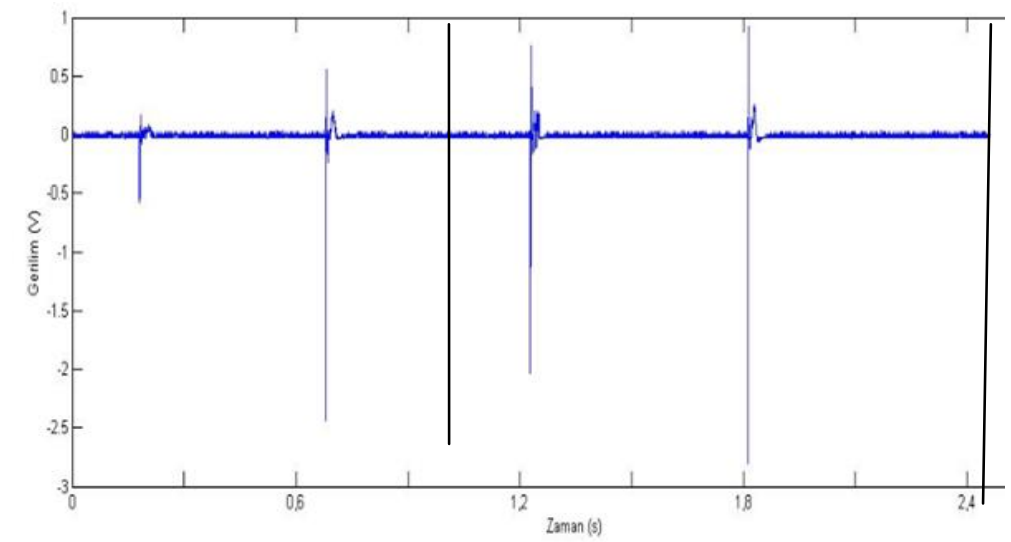

Şekil 9. Disk şeklindeki piezo elektriğin zamana bağlı değişimi,

\section{Sonuçlar}

Bugün dünya üzerinde gerçekleşen her eylemde bir şekilde enerji tüketilmektedir. $\mathrm{Bu}$ enerjilerin büyük bir kısmı sonlu (dönüşümsüz, tükenebilir) enerjilerden sağlanmaktadır ve zararlarının boyutları insan sağlığını tehdit edecek seviyelere ulaşmıştır. Günümüzde fabrikalarda üretim, otomatik çalışan makinelerle yapılıyor. Ancak bu makinelerin kontrolü elektronik ve bilgisayarlı sistemlerle gerçekleştiriliyor. Makinelerde oluşan mekaniksel ve fiziksel değişimleri bilgisayar sistemine aktarıp bilgisayar sisteminde işlenip tekrar aynı makinenin ya da başka makinelerin kontrolünü yapmak mümkündür. İşte sensörler bu noktada devreye girmektedir. Ortamda bulunan fiziksel bir değişikliği elektrik sinyallerine çevirerek elektronik sistemlere aktarmak için sensörleri kullanılmaktadır. Bunlara birkaç örnek verecek olursak, ürünlerin sayılmasında, kalite kontrolünün yapılmasında, ortamdaki sıcaklığın nemin ya da 1şığın belli bir değer aralığında tutulmasında hep sensörleri (algılayıcıları) kullanılmaktadır. Sensörler sadece endüstriyel firmalarda kullanılan cihazlar değildir; günlük hayatımızda da bizi değişik ortamlarda sürekli gözleyen gözler gibidir. Kablosuz klavyeler genellikle küçük radyo vericileri içerir. Herhangi bir radyo vericisi gibi, onları çalıştırmak içinde güç gerekir. Kablosuz klavyelerin pillerinin zaman zaman değiştirilmesi şarttır. Eğer sık sık klavye kullanıyorsanız, her yıl pilleri iki ya da üç kez değiştirmeniz gerekmektedir. Pillerin değiştirilmesi, pahalı olmasa da onlara önemli bir projenin ortasında pillerin tükenmesi, büyük bir sorunu ortaya çıkarmaktadır. Aynı zamanda pil atıkları, içerdikleri civa, kurşun, çinko, kadminyum gibi zararlı maddelerle toprağı kirletmekte ve insan sağlığına zarar vermektedir İşte bu çalışmada elektronik bir aygıt olan klavyeden kullanılmayan mekanik enerjiden elektrik enerjisi üretilme işlemi piezo elektriksel malzeme yardımıyla incelenmiş olup kuvvet gerilim dönüşümleri yapılmış ve klavyeye enerjisini veren pillere alternatif çözümler 
üretilmeye çalışılmıştır. Yapılan deneyler sonucunda klavye tuşları üzerine uygulanan $5 \mathrm{~N}$ kuvvetin yay vasıtasıyla tüm yüzeye ileterek farklı tiplerde yerleştirilen piezo elektrik malzemelerin atomları arasındaki hareket sağlanarak çeşitli gerilimler üretilmesi sağlanmıştır. Yapılan iki tasarımdan bir nolu tasarımın en yüksek gerilimi ürettiği tespit edilmiştir. Bir nolu tasarım da 14 V'luk gerilim ve 0,060 mA’lik bir akım çektiği gözlenmiştir. Yapılan hesaplamalar sonucunda üretilen gücün ortalama $840 \mu \mathrm{W}$ olduğu bulunmuştur. Bir pilin gerilim değeri şarj edilebilir piller için $1,2 \mathrm{~V}$ akım değeri ise $110 \mathrm{~mA}$ değerindedir. $\mathrm{Bu}$ değerlerden pilin gücü $132 \mathrm{~mW}$ olarak bulunur. Bu güç değerine ulaşabilmek pili şarj edebilmek için yaklaşık bir klavye tuşuna yaklaşık 158 kez basılması gerekmektedir. Birden fazla tuşta bu sistemin kullanılması durumunda bu sayı çok daha azalacaktır.

Sonuç olarak bu çalışma ile, kablosuz klavyede yer alan pil sorunu ve pillerin çevreye verdiği zarar önlenmiş olup kendi enerjisini üretebilen piezo elektrik yapılı bir klavye tasarlanmıştır.

Teşekkür: Bu çalışma Marmara Üniversitesi, Bilimsel Araştırma Projeleri Koordinasyon Biriminin (BAPKO) FEN-C-YLP 191212-0356 (Proje Ad1 Kendi Enerjisini, Üretebilen Klavye Tasarımı) numaralı projesi ile desteklenmiştir.

\section{KAYNAKÇA}

[1] Çelik B.G.:’Bina Düşey Kabuğunda Fotovoltaik Panellerin Kullanım İlkeleri, Gazi Üniv. Müh. Mim. Fak. Dergisi, Cilt 17, No 3, (2002), 17-33

[2] Raghavan, A.; Cesnik, S.E. C.:"Review of Guided-wave Structural Health Monitoring", The Shock and Vibration Digest, Vol. 39, No. 2, (2007) 91-114.

[3] Sodano, A.H.; Inman, D. J.:" Comparison of Piezoelectric Energy Harvesting Devices for Recharging Batteries", Journal of Intelligent Material Systems and Structures (2005) 799-801.

[4] Beeby, S . P.; Tudor, M. J.; White, N. M.:" Energy harvesting vibration sources for microsystems applications", Meas. Sci. Technol., Vol.17, (2006), 175-176.

[5] Rofouei, M.; Potkonjak, M.; Sarrafzadeh M.: Energy Efficient E-Textile Based Portable Keyboard" Proceedings of the 17th IEEE/ACM international symposium on Low-power electronics and design , (2011),339-344.

[6] Beker, L.; , Zorlu, Ö.; Külah, H.; Muhtaroğlu, A.: "Energy Harvesting From Keyboard", Energy Aware Computing (ICEAC), International Conference on IEEE, (2011), 8-11.

[7] Munson, J. B.: "Electrostatic Discharge Protection Measures for Membrane Keyboards", IEEE Transactions on Industry Applications, Vol. 18-20, No. 4, (1984)

[8] Zorlu, O.; Topal, E.T.; Kulah H.; “A Vibration-Based Electromagnetic Energy Harvester Using Mechanical Frequency Up- Conversion Method," IEEE Sensors Journal, Vol. 11, (2011), 481-488. 
[9] Shung, K. K.; Cannata, M. J.; Zhou, Q. F.:” Piezoelectric materials for high frequency medical imaging applications: A review", J Electroceram (2007) 19: 139-145.

[10] Kulah, H. ; Muhtaroglu, A.: "Piezoelectric cantilever prototype for energy harvesting in computing applications", Energy Aware Computing (ICEAC), International Conference on IEEE (2011), 1-4.

[11] Ottman, G.K.; Hofmann, H.F.; Lesieutre, G.A.: "Optimized piezoelectric energy harvesting circuit using step-down converter in discontinuous conduction mode", Power Electronics, IEEE,Vol.18,696-703.

[12] Anton, R.S.; Sodano, A.H.:"A review of power harvesting using piezoelectric materials”, Smart Mater. Struct. Vol. 16 doi:10.1088/0964-1726/16/3/R01 (2007).

[13] Lang, S.B.; Muensit, S. : "Review of some lesser-known applications of piezoelectric and pyroelectric polymers", Appl. Phys. A 85, (2006) 125-134.

[14] Nuffer, J.; Bein, T.: “Application of piezoelectric materials in transportation industry", Global Symposium on Innovative Solutions for the Advancement of the Transport Industry, San Sebastian, Spain (2006), 4.-6.

[15]. Sodano, A. H.; Lloyd, J.; Inman, D. J.:" An experimental comparison between several active composite actuators for power generation", Smart Materials And Structures.Vol 19 (2006), 1211-1213.

[16]. Priya, S.:" Advances in energy harvesting using low profile piezoelectric transducers", Electroceram (2007) 165-166.

[17] Usakli, A.B.; Gurkan, S.; "Design of a Novel Efficient Human-ComputerInterface: An Electrooculagram BasedVirtual Keyboard “, IEEE Transactıons on Instrumentatıon and Measurement, VOL. 59, NO. 8, (2010), 2099-2108.

[18] Buchberger, G.; Schwödiauer, R.; Arnold, N.; Bauer, S.:" Cellular Ferroelectrets for Flexible Touchpads, Keyboards and Tactile Sensors", Sensors IEEE (2008), 1520-1523.

[19] Bai, Y.W.; Yang, M.Y.: “An Improved Design of a Wireless Keyboard Powered by Solar Cells and a Large Capacitor", IEEE (2008), 1355-1357.

[20] Wacharasindhu, T.; Kwon, J. W.: "A micromachined energy harvester from a keyboard using combined electromagnetic and piezoelectric conversion", Micromech. Microeng. Vol.18 (2008) .

[21] Lallart, M.; Inman, J.D.: "Mechanical effect of combined piezoelectric and electromagnetic energy harvesting", Conference Proceedings of the Society for Experimental Mechanics Series, Vol.10, (2011), 261-272.

[22] Erturk, A.; Inmann, D.J.: "On Mechanical Modeling of Cantilevered Piezoelectric Vibration Energy Harvesters," Journal of Intelligent Material Systems and Structures, Vol. 19, 2008 1311-1325 .

[23] Shepherd S.J.;"Continuous authentication by analysis of keyboard typing characteristics," in European Convention on Security and Detection, (1995), 111-114.

[24] Choi, S.B.; Yoo, J.K.; Cho, M.S.; Lee, Y.S.:" Position control of a cylinder system using a piezoactuator-driven pump", Mechatronics (2005) 23-25.

[25] Wang, D.; Liu, Z.:" A shear mode piezoelectric energy harvester based on a pressurized water flow", ScienceDirect (2011), 449-458. 
[26] Yünlü, L. ,’Piezoelektrik Malzemeler ve Teknolojideki Kullanım Alanları”, Süleyman Demirel Üniversitesi Fen Bilimleri Enstitüsü, Yüksek Lisans Semineri, (2006),40-60.

[27] Doğrukol, S.," Piezoelektrik Malzemelerin Bünye Denklemleri”Süleyman Demirel Üniversitesi Fen Bilimleri Enstitüsü, Yüksek Lisans Tezi, (2002), 107-108.

[28] www.americanpiezo.com/knowledge-center/piezotheory/piezoelectricity.html, (2014) 